\title{
Comentario jurídico de la Ley 7/2020, de 31 de agosto, de Bienestar, Protección y Defensa de los Animales de Castilla-La Mancha. [2020/6154] - Diario Oficial de Castilla La-Mancha de 07-09-2020
}

Fecha de entrada en vigor: 07/03/2021

Órgano Emisor: Presidencia De La Junta

Boletín: Diario Oficial de Castilla-La Mancha Número 180

Fecha de Publicación: 07/09/2020

Laure Gisie

Doctoranda en Derecho Animal

Miembro del ICALP

Universitat Autònoma de Barcelona

Cita recomendada. GISIE, L., Comentario jurídico de la Ley 7/2020, de 31 de agosto, de Bienestar, Protección y Defensa de los Animales de Castilla-La Mancha. [2020/6154] - Diario Oficial de Castilla-La Mancha de 07-09-2020, en dA. Derecho Animal (Forum of Animal Law Studies) 12/1 (2021). - DOI https://doi.org/10.5565/rev/da.556

Resumen

En Castilla-La Mancha hay muchos hogares con animales. Entre ellos, el perro es particularmente apreciado por su compañía, pero también puede serlo por sus increíbles cualidades de cazador o guardián, por nombrar solo algunas habilidades caninas. Una ley reciente de agosto de 2020 viene a regular el bienestar y la protección de los animales en la región. Los perros podrán disfrutar de medidas inéditas teniendo en cuenta nuevas obligaciones y prohibiciones aplicables a los dueños, pero también podrán experimentar con nuevos aliados como el Consejo Asesor de Bienestar y de Protección Animal.

Palabras clave: Perro; Comportamiento canino; Galgo; Tenencia responsable; Bienestar animal.

Abstract - Legal commentary on Law 7/2020, of August 31, on the Welfare, Protection and Defense of the Animals of Castilla-La Mancha. [2020/6154] - Official Gazette of Castilla La-Mancha of 07-09-2020

In Castilla-La-Mancha, there are many homes with animals. Among them, dogs are particularly appreciated for their company, but it could also be so for their incredible qualities as hunters or guardians, to name just a few canine abilities. A recent law of August 2020 has come to regulate the welfare and protection of animals in the region. Dogs will be able to enjoy unprecedented measures taking into account new obligations and prohibitions applicable to owners, but they will also be able to experiment with new allies such as the Advisory Council on Welfare and Animal Protection.

Keywords: Dog; Dog behaviour; Greyhound; Responsible ownership; Animal welfare. 
Castilla-La Mancha decidió ordenar legislativamente la protección y defensa de los animales domésticos promulgando la Ley 7/1990, de 28 de diciembre, de Protección de los animales domésticos ${ }^{1}$. Pero recientemente se acaba de elaborar una nueva ley mucho más moderna para tener en cuenta las nuevas demandas de la sociedad en términos de bienestar animal. El texto emitido por las Cortes de Castilla-La Mancha entrará en vigor el 7 de marzo de 2021.

En los últimos años, se ha incrementado el número de animales domésticos en los hogares. Contando sólo a los perros, el 24,8 por ciento ${ }^{2}$ de los hogares españoles los poseen. A esta cifra deberían añadirse gatos y, por supuesto, nuevas mascotas exóticas que están aumentando sin tener normas jurídicas de protección fiables. El legislador autonómico no ha sido ajeno a la realidad social de su tiempo, como así pone de manifiesto en su exposición de motivos y podemos ver que así lo tiene en cuenta ${ }^{3}$. En su artículo 3, la ley prevé una definición de estos nuevos animales, definidos como "animales de la fauna salvaje no autóctona que de manera individual dependen de los humanos, conviven con ellos y han asumido la costumbre del cautiverio".

La Ley 7/2020, de 31 de agosto, de Bienestar, Protección y Defensa de los Animales de Castilla-La Mancha va más allá de la protección de los animales domésticos. En efecto, encontramos la prohibición del empleo de animales de fauna silvestre y salvaje en el circo. Existe un consenso real a nivel europeo sobre este tema porque cada vez más países están tomando la decisión de impedir la exhibición de animales salvajes en los circos. El objetivo de aumentar el bienestar de los animales es una demanda de la sociedad. Por eso se ha aprobado una nueva ley más amplia y que parece más moderna. Lamentablemente, si bien el texto tiene algunos puntos muy positivos, también podemos ver que no se aplica a todo tipo de animales. En efecto, hay que referirse a la legislación específica para la fauna silvestre, especies exóticas invasoras, las aves de cetrería, los animales de producción, los utilizados en espectáculos taurinos, experimentación, otros fines científicos y también para los animales existentes en los parques zoológicos.

Como el perro vive en muchos hogares de España y es un animal muy apreciado por su labor y sus cualidades como guardián, cazador y auxiliar de seguridad, entre otras, en este articulo se verá hasta qué punto la Ley 7/2020, de 31 de agosto, de Bienestar, Protección y Defensa de los Animales protege a los perros en la región de Castilla-La Mancha. Para responder a este interrogante, habría que estudiar la finalidad de la ley y ver en profundidad las obligaciones y prohibiciones previstas para el efecto.

\section{Finalidad de la Ley 7/2020, de 31 de agosto, de Bienestar, Protección y Defensa de los Animales de Castilla-La Mancha}

En primer lugar, cabe subrayar la importancia del contenido del artículo 2 de la ley donde expresa su pretensión de asegurar el bienestar de estos animales por su condición de seres sintientes. Es un punto interesante porque hace referencia al movimiento de descosificación de los animales y a su régimen jurídico, actualmente paralizado, en la propuesta de ley de modificación del Código Civil y otros textos normativos sobre el régimen jurídico de los animales ${ }^{4}$.

La actual regulación de los bienes del Código Civil otorga a los animales el estatuto jurídico de cosas y, más en detalle, de bienes muebles sin hacer referencia a la sintiencia de los animales. El termino "sintiencia" viene de la locución latina sentiens (sentimiento) y significa para un ser vivo tener la capacidad de sentir emociones, dolor, bienestar, etc. y de percibir subjetivamente su entorno y sus experiencias vitales 5 . Reconocer a los animales como "seres sintientes" permite ponerse en conformidad con los estándares europeos y en particular con el artículo 13 del TFUE que prevé que los Estados miembros deben tener en cuenta las exigencias en materia de bienestar de los animales como seres sensibles.

Sin embargo, es absolutamente necesario recordar que no todos los animales gozan de la protección de esta ley, como se establece en el artículo 1.2. Por lo tanto, es esencial señalar la falta de protección de los

\footnotetext{
${ }^{1}$ Comunidad Autónoma de Castilla-La Mancha «DOCM» núm. 1, de 2 de enero de 1991 «BOE» núm. 93 , de 18 de abril de 1991 Referencia: BOE-A-1991-9406: https://www.boe.es/buscar/pdf/1991/BOE-A-1991-9406-consolidado.pdf

2 DIAZ, A. Porcentaje de hogares que tenían perro en España de 2008 a 2019. Statista. Página web :

https:/es.statista.com/estadisticas/1045371/porcentaje-de-hogares-con-perro-en-espana/ [Última consulta : 25 de noviembre de 2020]

${ }^{3}$ Desde entonces -refiriéndose a la anterior Ley de 28 de diciembre de 1990- el aumento de la tenencia doméstica de especies distintas de las tradicionalmente consideradas como animales de compañía, así como el rechazo de la sociedad al sacrificio de animales, unido al incremento de actividades económicas y comerciales relacionadas con los mismos hace necesario fijar, en el marco de las competencias de la comunidad autónoma, una nueva norma que responda a estos nuevos aspectos.

${ }^{4}$ Boletín Oficial de las Cortes Generales, Congreso de los Diputados, XII Legislatura, Proposiciones de ley, 1 de marzo de 2019, Núm. 167-5, 122/000134, Proposición de Ley de modificación del Código Civil, la Ley Hipotecaria y la Ley de Enjuiciamiento Civil, sobre el régimen jurídico de los animales: http://www.congreso.es/public_oficiales/L12/CONG/BOCG/B/BOCG-12-B-167-5.PDF

${ }^{5}$ GUILLAUME, A., Le poids des mots/maux autour de la sentience animale : différences sémantique et traductologique entre bienêtre et bientraitance, en Le bien-être animal : de la science au droit. (2018) 69-80.
} 
animales utilizados en las actividades de caza, incluidos los perros que son auxiliares del cazador. Según el articulo 4.1. h) de esta ley, la acción de cazar no se considera como situación de peligro ni de maltrato. Es sintomático que las normas jurídicas añadan estas precisiones, aunque resulta claro que la acción de cazar pone en peligro a los animales y constituye maltrato.

En el mismo artículo 2 se observa que, dentro de la finalidad de la ley, entra la prioridad de la defensa de los animales en todas las situaciones que les causen un daño físico y conductual, así como las que no aseguren un trato adecuado a cada animal. El daño físico no es en modo alguno una novedad y los animales están ampliamente protegidos de él; por otro lado, el daño moral es bastante nuevo y consecuencialmente se encuentran dificultades para comprender qué debería incluirse en esta categoría.

Si acudimos al artículo 3 de la ley se nos da la siguiente definición de maltrato: "Cualquier conducta, tanto por acción como por omisión, mediante la cual se somete a un animal a dolor, sufrimiento o estrés grave." Por tanto, podemos pensar que el maltrato se refiere también a todo dolor, sufrimiento o estrés emocional grave, es decir, el daño grave a sus emociones. Con el término conductual se entiende la parte emocional del animal. En esta categoría podrá entonces entrar, por ejemplo, una persona que deja a su perro encerrado mucho tiempo o que no le da actividad social. No es un daño físico como un golpe, aunque este también puede conllevar daño emocional porque están relacionados. Estos influyen en la conducta del perro.

\section{Las obligaciones hacia los animales}

La nueva ley implementa obligaciones para el poseedor y para el titular de un animal que es objeto de protección. Estas obligaciones incluyen medidas básicas como la obligación de alimentarlo, identificarlo, colocarlo en un lugar que lo proteja de las inclemencias del tiempo y la obligación de tener en cuenta sus necesidades etológicas. Pero también hay medidas más sorprendentes, como el hecho de "cuidar y proteger a los animales de las agresiones, situaciones de peligro, incomodidades y molestias que otras personas o animales les puedan ocasionar, en los casos que proceda".

A la lectura de este punto se destaca una idea novedosa parecida a la omisión del deber de socorro a las personas ${ }^{6}$. Sin embargo, el artículo proporciona una salvaguardia y dice que la acción de cazar no se considera a estos efectos situación de peligro ni maltrato, incluidos los animales auxiliares del cazador. Por tanto, los perros de caza y en particular los galgos, que son perros explotados excesivamente en España, no podrán disfrutar de esta protección. Es un verdadero acto fallido.

Del mismo modo, otra medida novedosa es la obligación de educar y socializar a los animales de compañía. Según el Estudio sobre Abandono y Adopción de animales de compañía del año $2018^{7}$, los propietarios que entregan a su animal de compañía a un refugio lo hacen en un 10,8 por ciento por comportamiento del animal, la tercera razón después de las camadas no deseadas $(15,3 \%)$ y el fin de la temporada de caza $(12,6 \%)$. Es un punto importante porque el abandono es el principal problema de bienestar de los animales de compañía en España.

\section{Las prohibiciones para proteger a los animales}

Tenemos derechos y deberes hacia los animales, pero también necesitamos limitaciones porque las conductas de las personas pueden dañarles. Con respecto a las prohibiciones de la Ley 7/2020, de 31 de agosto, de Bienestar, Protección y Defensa de los Animales de Castilla-La Mancha, podemos ver una protección general de la vida del animal con la imposibilidad de causar la muerte a los animales, prohibiéndose por la letra b) del articulo 5 de la ley. En la nueva norma, cabe destacar la voluntad de lograr el sacrificio cero.

Adicionalmente, en la letra a) del articulo 5 de la ley se ilustra el deseo de proteger al animal de todas las formas de sufrimiento que sean daños físicos o comportamentales. Para una mejor protección de estos animales es importante tener en cuenta las consecuencias morales, aunque a veces sean más difíciles de detectar. Los sufrimientos innecesarios están prohibidos, como las intervenciones quirúrgicas y mutilaciones cuyo objetivo sea modificar la apariencia de un animal.

Durante un tiempo, muchas razas de perros fueron mutiladas sistemáticamente para ser fieles al estándar de la raza. Se cortaron las colas y las orejas de los Doberman para que pareciesen más agresivos. Cortamos la cola de los caniches para poder hacer un pompón de pelo que consideramos lindo. Otros practican la succión

\footnotetext{
${ }^{6}$ Título IX del Libro II, integrado por los artículos 195 Y 196 del Código Penal.

${ }^{7}$ Estudio sobre Abandono y Adopción de animales de compañía del año 2018, publicado por la Fundación Affinity en 2019. Página wab: https://www.fundacion-affinity.org/observatorio/whitepaper-el-nunca-lo-haria-2019-estudio-abandono-adopcion-perros-gatosespana [Última consulta : 20 de noviembre de 2020].
} 
de las cuerdas vocales para evitar los ladridos o la extirpación de uñas y dientes para proteger su sofá. Estas prácticas son cada vez menos comunes pero es importante prohibirlas en los textos legislativos. Por supuesto, todavía está autorizado si el acto tiene fines curativos en relación a la medicina veterinaria.

En este sentido, hay intervenciones quirúrgicas que impiden la reproducción para disminuir los abandonos. También existen actos quirúrgicos para aliviar a un animal, por ejemplo los problemas de algunas razas de perros vinculados a la cría. En efecto, la cría de animales de compañía es una actividad económica que goza de una gran popularidad y los criadores de determinadas razas trabajan constantemente con la genética del animal para obtener un rasgo físico particular.

Es el caso del Bulldog francés. Los criadores quieren mantener la nariz más aplastada para sus nuevos cachorros. A fuerza de selecciones excesivas para darles ese aspecto, los perros quedan discapacitados con problemas en los ojos, oídos, piel y, sobre todo, complicaciones respiratorias ${ }^{8}$. Estos perros a menudo necesitan cirugía para brindar alivio. Es un caso que la ley permitiría, pero tendríamos que ir más allá controlando estos juegos genéticos que son peligrosos para nuestros animales y constituyen un verdadero maltrato.

En las prohibiciones que se establecen en el artículo 5 de la ley, se destaca también el hecho de mantenerles permanentemente atados, encadenados o encerrados, por tiempo o condiciones, que puedan hacer sufrir a los animales. Esta disposición señala el fin de los animales utilizados con fines puramente utilitarios, como aquellos usados para vigilar parcelas o granjas.

Otro punto interesante es que con esta ley no se permite vender, donar o ceder los animales a menores o a incapacitados sin la autorización de quien tenga la patria potestad, custodia o tutela legal. Este punto puede ser beneficioso para evitar compras compulsivas al exigir un guardia con un adulto o persona responsable que pueda atender el deseo de la persona bajo tutela del menor. Tampoco se puede hacer donación de animales como reclamo publicitario, recompensa, premio o rifa. La ley aquí reconoce que el animal es un ser sensible y que ya no debe ser reconocido por su valor de mercado en un caso concreto como este.

La letra j) del mismo artículo 5 de la nueva Ley 7/2020, de 31 de agosto, de Bienestar, Protección y Defensa de los Animales de Castilla-La Mancha prevé otras prohibiciones estrictas por suministrar sustancias que puedan causar sufrimientos o daños innecesarios y alteración de su salud y comportamiento, así como cualquier tipo de sustancia no autorizada. Esta medida permite reglamentar aspectos intrínsecos al deporte de animales de competición que son los problemas de dopaje, pero no tiene nada de novedoso porque es una disposición que ya existe en la mayoría de los textos que protegen a los animales.

Por ejemplo, la medida está escrita casi idénticamente en la Ley 11/2003, de 19 de marzo, de Protección Animal en la Comunidad Autónoma de Aragón ${ }^{9}$. En las normas de la Comunidad Autónoma del País Vasco, es el artículo 4 el que prevé responsabilidades del personal del entorno de los deportistas y de los animales que participan en competiciones deportivas ${ }^{10}$. Se destaca de los textos una responsabilidad hacia los animales de los entrenadores, instructores, directores, propietarios, pero también del personal médico que tienen un papel importante para controlar el dopaje animal.

Los animales se utilizan a menudo en deportes o en actividades de ocio para responder a una necesidad humana. Los perros suelen pagar el precio de este deseo humano. A algunas personas le gustan hacer agility, dog dancing, carreras, actividades de caza, por nombrar solo las actividades más populares. Entre las más invasivas y peligrosas están las que organizan peleas. La ley de Castilla-La Mancha prevé la prohibición de cualquier forma de peleas con animales.

En cuanto a las actividades de ocio, la ley prevé en su apartado sobre prohibiciones la interdicción de atar animales a los vehículos de motor en movimiento, salvo en los casos de galgos en los que el animal esté sujeto en la parte delantera del vehículo y la velocidad del mismo no supere los $15 \mathrm{~km} /$ hora. Por lo tanto, el principio es la prohibición consistente en el hecho de respetar al animal pero, como sucede a menudo, está seguido por una excepción que se hace aquí para los galgos. Es una decisión escandalosa desde el punto de vista de la protección de los perros.

A menudo, los lebreles están entrenados para correr detrás de un vehículo a motor, lo que causa agotamiento y lesiones. A veces el perro incluso se derrumba por la fatiga y es arrastrado durante unos metros de distancia. Una vez más, el lobby de la caza y de los galgueros ${ }^{11}$ han logrado hacer cumplir su voluntad a pesar de que el texto reconoce en principio que esta acción no debe permitirse. Ciertamente podemos pensar

\footnotetext{
${ }^{8}$ Breed-Specific Respiratory Disease In Dogs: From Bulldogs To Terriers. Página web: https://todaysveterinarypractice.com/breedspecific-respiratory-disease-dogs-bulldogs-terriers/?fbclid=IwAR3fSupRmy3gBeve5jZiVjxIRILS2-

wFJ2PtHkJAxdL3hcYKdTnwVjrIsWY 5 [Última consulta: 6 de diciembre de 2020].

${ }^{9}$ Ley 11/2003, de 19 de marzo, de Protección Animal en la Comunidad Autónoma de Aragón.

${ }^{10}$ Ley 12/2012, de 21 de junio, contra el Dopaje en el Deporte.

11 Comunicado de la FEG que agradece el trabajo de los cazadores para la implantación de esta medida. Página web: https://www.fedegalgos.com/la-ley-de-bienestar-animal-castellano-manchega-permite-el-entrenamiento-de-galgos-con-vehiculos-amotor/ [ Última consulta: 20 de noviembre de 2020]
} 
que el descenso a quince kilómetros por hora es una salvaguarda para no herir a los galgos. embargo, ¿habrá controles reales?

Además, para que la excepción sea verdaderamente protectora, falta una cierta cantidad de elementos, como la prohibición del ejercicio en tiempo de calor, una edad mínima para el perro (cuando sabemos que un cachorro debe tener una actividad muy moderada durante la duración de su crecimiento) e incluso protección para perros ancianos. Tampoco hay limitación de tiempo o de kilómetros recorridos. Esta excepción no tiene cabida en una ley de protección animal.

No obstante, podemos subrayar la prohibición prevista en la ley de disparar o agredir a los animales con armas de fuego, de aire o gas comprimido, ballestas, arcos, armas blancas o cualquier otra que ponga en riesgo su vida. En la práctica, los galgos que ya no son utilizados por los cazadores, ya sea porque son demasiado mayores o porque no cazan, suelen ser asesinados con armas directamente por su dueño. Incluso puede ocurrir que el perro cace con demasiada inteligencia y que corte la pista durante su carrera. En este caso el galgo será descalificado y los cazadores lo considerarán sucio ${ }^{12}$, lo que puede provocar una muerte trágica dada por el dueño. Por supuesto, esto es ilegal y esta ley lo recuerda, pero en la práctica a menudo es difícil encontrar a los perros y los dueños casi nunca son condenados.

\section{La identificación: una herramienta fundamental para fomentar su tenencia responsable}

La identificación de los animales permite encontrarlos en caso de pérdida y también encontrar y condenar al propietario en caso de abandono o crueldad hacia el animal, pero en la práctica son sólo el 34,3 por ciento ${ }^{13}$ de los perros que llegan identificados a la protectora.

En materia de identificación animal, hay una novedad a destacar que es innovadora. Hasta ahora, la legislación autonómica ha establecido un sistema de doble registro, uno autónomo y otro en cada uno de los municipios, a través del censo municipal, donde habitualmente vive el animal. Gracias a esta nueva ley, cambiamos de paradigma para tener un registro único gestionado por el Consejo de Colegios Profesionales de Veterinarios de Castilla-La Mancha bajo las directivas de la Dirección General del Ministerio con competencias en materia de identificación y registro de animales.

Según la nueva ley de Castilla-La Mancha, los perros, gatos y hurones deberán ser identificados individualmente antes de los tres meses de edad. Para finalizar correctamente el acto de identificación, a continuación del marcaje se procederá a solicitar telemáticamente por el veterinario el alta en el Registro de Identificación de Animales de Castilla-La Mancha, con la inclusión de los datos del titular del animal y del veterinario actuante, en el plazo máximo de tres días hábiles.

Se destaca una doble condición: la identificación con el microchip y la inscripción al registro. Estas condiciones acumulativas deben cumplirse, de lo contrario puede incurrir en responsabilidad del veterinario.

El problema es que a veces se puede trasladar al animal sin que se avise a este. Entonces será responsabilidad del nuevo propietario que tendrá que solicitar el cambio de titularidad al Registro de Identificación en el plazo máximo de tres días hábiles a contar desde el día en que la posesión del animal esté operativa. Este plazo de tres días hábiles se debe respetar también en caso de muerte del animal.

\section{Facilitar el acceso a las mascotas en nuestra sociedad}

Una vez identificados, podemos aprovechar y llevar a nuestros animales a todas partes con nosotros. Para ayudarnos, la nueva ley quiere desarrollar que los transportes públicos y privados deban posibilitar la entrada de animales de compañía.

La medida es fundamental porque sin acceso al transporte hay una verdadera brecha de igualdad. Además, por motivos ecológicos, esta es una medida notable, por lo que los dueños de perros ya no tendrán que llevar sistemáticamente el coche para pasear o ir al veterinario.

El texto agrega que los alojamientos hoteleros, los restaurantes, los bares y aquellos otros en los que se consuman bebidas y comidas, facilitarán la entrada de animales de compañía. Nuestros animales viven cada vez más en las ciudades y se convierten en verdaderos ciudadanos de nuestra sociedad. Por eso, deben poder acceder a los establecimientos de la ciudad. Por supuesto, este privilegio debe ir acompañado de medidas de seguridad: nuestro animal debe ser capaz de comportarse en sociedad y tener una base de educación para que humanos y animales puedan vivir en total armonía.

\footnotetext{
12 GAEDE, C. EBBRECHT, T. Galgo español - Le lévrier Espagnol (2019) 93.

${ }^{13}$ FATJÓ, J. Estudio "El nunca lo haría" de la Fundación Affinity sobre el abandono, la pérdida y la adopción de animales de compañía en España 2018: interpretación de los resultados. Página web: https://www.fundacion-affinity.org/sites/default/files/white-paperabandono-2019.pdf [Última consulta : 18 de noviembre de 2020]

116 Derecho Animal. Forum of Animal Law Studies, vol. 12/1
} 


\section{La tenencia y el adiestramiento de los perros}

Tener un animal es ante todo tener responsabilidades. Hay que cubrir las necesidades del perro, alimentarlo adecuadamente, identificarlo como hemos visto anteriormente, pero también hay que pensar en la esterilización. La Ley 7/2020, de 31 de agosto, de Bienestar, Protección y Defensa de los Animales de CastillaLa Mancha prevé que se deben adoptar las medidas necesarias para evitar las reproducciones indeseadas de animales con una tenencia responsable de los mismos y añade que, si no es posible esta tenencia responsable, se deberá esterilizar a los animales.

Cada año hay camadas no deseadas. Es un verdadero problema saber que una perra suele tener varias crías al mismo tiempo. Esta es una problemática real que vuelve a aumentar los abandonos. Pero finalmente, ¿deberíamos detenernos en las camadas no deseadas? También hay personas no profesionales que sueñan con criar con su perro sin conocer los requisitos previos y que pueden poner en peligro a sus animales. Ser criador no se puede improvisar. El juego de la genética es complejo y hay reglas. Sabiendo esto, podemos preguntarnos sobre la necesidad de dar a luz nuevos perros solo por deseo cuando los refugios ya están llenos. La cría debería ser monopolio de los profesionales.

Una vez que el animal ha nacido es necesario comenzar con su educación lo más rápido posible. Algunas personas querrán una educación básica; otras se centrarán en el adiestramiento canino de acuerdo con sus necesidades, por ejemplo para perros de caza, perros de seguridad o perros de carreras. En virtud de la Ley 7/2020, de 31 de agosto, de Bienestar, Protección y Defensa de los Animales de Castilla-La Mancha, los procedimientos de trabajo de los adiestramientos deben estar basados en métodos que no entrañen la utilización de malos tratos ni comprometan la salud y el bienestar de los animales.

Los centros y lugares donde se realicen estos adiestramientos deben estar inscritos como núcleos zoológicos. Esta medida permite homogenizar con el Convenio Europeo sobre protección de animales de compañía, hecho en Estrasburgo el 13 de noviembre de $1987^{14}$. No existe ninguna normativa a nivel estatal que regule el adiestramiento canino ${ }^{15}$. Esta es una falta real porque vemos un problema con el entrenamiento de los adiestradores de perros. Las capacitaciones no están suficientemente supervisadas y muchas asociaciones denuncian los actos crueles realizados por algunos educadores. La coerción ya no debería ser la norma y la formación de los educadores debe rediseñarse por completo.

Debemos repensar nuestra relación con los animales y establecer una relación de confianza con ellos. Deben obedecer por envidia, por juego, por amor y no por dolor o miedo. ¿Quid de los collares estranguladores y de los collares eléctricos? Todavía se utilizan mucho en los lugares de adiestramientos para educar a los perros. Las herramientas coercitivas son muy efectivas ya que el animal no tiene más remedio que cumplir con la demanda. Sin embargo, es un método que no respeta el bienestar animal.

El uso del collar de estrangulamiento es peligroso ya que causa dolor en el cuello y las vértebras cervicales. El collar eléctrico es aún peor ${ }^{16}$. Además, es responsable de muchas evoluciones agresivas, en particular ataques por irritación como el miedo o porque le duele el cuello, pudiendo llegar a tener problemas territoriales por asociación del dolor (debido al collar eléctrico) con el paso de alguien próximo a la valla.

Si la nueva ley prevé que no se adiestrará a ningún animal de compañía de tal modo que se perjudique su salud y bienestar, en particular obligándole a superar sus fuerzas o capacidades naturales o utilizando medios artificiales que provoquen lesiones, dolores, sufrimientos o angustias innecesarios, deberíamos pensar que las herramientas coercitivas ya no se deberían poder utilizar. La ley incluso llegó prohibir la venta y uso de objetos que causen lesión a los animales que están bajo nuestra responsabilidad: collares de pinchos o púas, de ahogo y los de descarga eléctrica, salvo por particulares bajo prescripción y control veterinario o para su uso en adiestramiento por profesionales cualificados. Es un buen primer paso hacia una educación respetuosa.

Desafortunadamente, todavía quedan permisos escandalosos, como por ejemplo el hecho de permitir que un animal sea atado de manera permanente. Aunque la ley obliga a que sus ataduras les deban permitir el movimiento, acostarse, levantarse, acceder a lugares de resguardo y a los recipientes de agua y alimento. Sin embargo, esto no es suficiente para satisfacer las necesidades de un perro, por ejemplo, paseos y contacto con sus semejantes porque es un animal social ${ }^{17}$. Un perro sano y de buen comportamiento tendrá más

\footnotetext{
${ }^{14}$ Instrumento de ratificación del Convenio Europeo sobre protección de animales de compañía, hecho en Estrasburgo el 13 de noviembre de 1987. «BOE» núm. 245, de 11 de octubre de 2017: https://boe.es/diario boe/txt.php?id=BOE-A-2017-11637

${ }^{15}$ En Inglaterra, existe una ley que contiene un código ético específico de adiestramiento canino: Animal Welfare Act (2006. Department for Environment Food and Rural Affairs).

${ }^{16}$ LOGAN, M. Training dogs with help of the shock collar: short and long term behavioural effects. AVSAB (2012)

${ }^{17}$ KOSCINCZUK, P. Domesticación, bienestar y relación entre el perro y los seres humanos. Revista Veterinaria. ISSN (2017) (papel): 1668-4834. ISSN (on line) 1669-6840.
} 
posibilidades de permanecer en su familia y así evitar el abandono. Todas las medidas deben estar vinculadas entre sí.

\section{Los centros de acogida y los motivos de sacrificio}

Según la nueva ley, las entregas voluntarias de animales a los centros de acogida no se consideran abandono siempre que la titularidad del animal se cambie en el correspondiente registro a favor del centro de acogida. Esto permite eximir al propietario de la persecución penal y alentar a estas personas a que vengan a dejar a sus animales en un sitio seguro en lugar de dejarlos en la carretera o, peor aún, matarlos. Esta es también la principal fortaleza de esta ley y la idea de llegar al sacrificio cero. Las únicas excepciones aceptadas para causar la muerte de un animal son en caso de motivos sanitarios, tanto de salud pública como de sanidad animal, constatadas en caso de motivo de seguridad personal, de otros animales o si los animales están afectados por enfermedades de carácter zoonótico, siempre que su tratamiento y aislamiento no sea posible. El sacrificio es la excepción, ya que el principio es la curación.

Sobre los centros de acogida, la Ley 7/2020, de 31 de agosto, de Bienestar, Protección y Defensa de los Animales de Castilla-La Mancha prevé que los animales que llegan allí, no podrán cederse o darse en adopción a personas que hubieran sido condenadas en virtud de sentencia penal firme por delitos relacionados con los animales regulados en esta ley en los tres últimos años, o sancionadas por resolución administrativa firme por infracciones graves y muy graves, en los dos años anteriores para el caso de infracciones graves y de tres años para las muy graves. Esta medida es sustancial, pero tendríamos que dar la información adecuada y actualizada a los refugios. Además, las personas que han sido condenadas por maltrato o crueldad animal deberían ser controladas periódicamente.

\section{La educación en bienestar animal: el comienzo de todas las soluciones}

La frase mítica de Gandhi que decía "Un país, una civilización se puede juzgar por la forma en que trata a sus animales" está anclada en cada mente. La Ley 7/2020, de 31 de agosto, de Bienestar, Protección y Defensa de los Animales de Castilla-La Mancha ha previsto que la Administración autonómica programe campañas divulgativas del contenido de la presente ley entre los escolares y habitantes de la Comunidad Autónoma de Castilla-La Mancha y promueva la inclusión de contenidos en materia de bienestar animal en los programas educativos aplicables en el ámbito territorial de esta Comunidad Autónoma.

Además, en colaboración con instituciones públicas, privadas y con entidades dedicadas a la protección de los animales, la Comunidad Autónoma realizará actividades formativas destinadas a los titulares y poseedores de animales con el fin de promover la tenencia responsable de los mismos. Los objetivos van encaminados a la reducción de la compra compulsiva de animales de compañía, de formar a las bases etológicas de los animales e incitar a la acción de esterilizar su animal.

\section{El Consejo Asesor de Bienestar y Protección de los Animales: una idea muy novedosa y útil}

Hasta ahora había Consejos Asesores en materia de medio ambiente, pero proporcionar esta entidad para los animales es algo muy innovador. El nuevo Consejo Asesor de Bienestar y de Protección de los Animales es un órgano colegiado de participación, consulta, información y asesoramiento sobre aspectos de interés y relacionados con el bienestar y la protección de los animales.

El Consejo se compone de una persona titular de la Consejería competente en materia de protección y bienestar animal y diez representantes de: la Consejería con competencias en materia de salud pública, las asociaciones de protección y defensa de los animales de Castilla-La Mancha, las asociaciones de protección del medio ambiente de Castilla La Mancha, los centros de acogida y mantenimiento de animales de CastillaLa Mancha, las asociaciones de cazadores de Castilla-La Mancha, el Servicio de Protección de la Naturaleza, la Administración estatal, la Federación de Municipios y Provincias de Castilla-La Mancha, el Consejo de Colegios Profesionales de Veterinarios de Castilla-La Mancha y la Universidad de Castilla-La Mancha.

El consejo es, por tanto, un organismo compuesto por una serie de numerosos profesionales que son competentes en diversos campos además de la protección de los animales. Sin embargo, es lamentable ver que hay pocos representantes de la causa animal, sabiendo que los representantes de la naturaleza o del medioambiente a menudo tienen experiencia sobre la conservación de especies y una visión ecológica pero no necesariamente son capaces de dar consejos en materia de bienestar animal. También es posible cuestionar la elección de tener un representante del mundo de la caza.

Este Consejo tiene muchas competencias útiles para actuar en materia de protección y bienestar de los animales. En efecto, puede emitir informe previo de carácter no vinculante a la aprobación de cualquier 
normativa relacionada con la protección de los animales. También puede emitir informes sobre los protocolos de actuación referidos en esta ley. Igualmente, tiene el papel de poder informar sobre la conveniencia de las autorizaciones por parte de la autoridad competente en bienestar animal de los sacrificios excepcionales y puede plantear iniciativas destinadas a la protección y mejora del bienestar de los animales. Además, para el mejor cumplimiento de sus misiones se podrán crear Grupos de Trabajo permanentes para el desarrollo o tratamiento de temas específicos.

\section{El procedimiento sancionador}

Para que el texto se aplique correctamente debe existir un régimen de sanciones. Las infracciones pueden ser sancionadas con multas de 300 a 60.000 euros en función de la gravedad (leves, graves, muy graves). La Ley 7/2020, de 31 de agosto, de Bienestar, Protección y Defensa de los Animales de Castilla-La Mancha ha previsto otras penas accesorias y medidas complementarias. Por ejemplo, podemos desvincular la medida que prevé el decomiso de los animales para las infracciones graves o muy graves, lo cual es muy importante para poner al animal a salvo rápidamente. Otra medida es la prohibición de la tenencia de animales por un período máximo de cinco años para las graves y muy graves, pero parece insuficiente y si los controles no son regulares. La persona en cuestión podrá retirar fácilmente un animal antes de este plazo que ya es muy corto.

Además, hablando de controles, conviene enfatizar que las inspecciones son importantes y que es necesario asegurar el buen funcionamiento de esta nueva ley. Los municipios deben ejercer la inspección y vigilancia de los animales situados en sus términos municipales, recoger, controlar y gestionar a los animales abandonados o perdidos y recoger y gestionar los cadáveres de los animales muertos. Además, la ley prevé que la Consejería competente en bienestar animal tiene que inspeccionar y controlar oficialmente los núcleos zoológicos con un programa de control anual, además de los controles necesarios y realizar denuncias.

\section{Reflexiones finales}

La Ley 7/2020, de 31 de agosto, de Bienestar, Protección y Defensa de los Animales de Castilla-La Mancha aparece como una nueva ley bastante moderna que tiene en cuenta el carácter sensible y sintiente de los animales. La ley está especialmente bien elaborada para proteger a las mascotas y especialmente para proteger a los perros. Lamentablemente, aquí también hay algunas deficiencias, ya que si nuestros perros de compañía están bien alojados gracias a esta ley, no es el caso de los perros de trabajo y especialmente los perros que ayudan a la caza. Los galgos vuelven a ser excluidos para poder servir a los propósitos de los cazadores.

Incluso si el sistema de sanciones está bien pensado, las penas siguen siendo intrascendentes y algunas infracciones entran en la categoría de infracciones leves, si bien pueden ser devastadoras en la vida del perro o animal. Es el caso de la falta de tratamientos sanitarios, el hecho de no facilitar a los animales alimentación adecuada a sus necesidades y la utilización y uso de objetos que causen lesión a los animales.

No obstante, se trata de un texto que permitirá una mayor responsabilidad de los propietarios de los animales y permitirá establecer unas mejores condiciones de vida para ellos en la región de Castilla-La Mancha.

\section{Referencias}

\subsection{Fuentes jurídicas}

- Boletín Oficial de las Cortes Generales, Congreso de los Diputados, XII Legislatura. Proposiciones de leyes, 1 de marzo de 2019, Núm. 167-5, 122/000134, Proposición de Ley de modificación del Código Civil, la Ley Hipotecaria y la Ley de Enjuiciamiento Civil, sobre el régimen jurídico de los animales: http://www.congreso.es/public_oficiales/L12/CONG/BOCG/B/BOCG-12-B-167-5.PDF

- Instrumento de ratificación del Convenio Europeo sobre protección de animales de compañía, hecho en Estrasburgo el 13 de noviembre de 1987. «BOE» núm. 245, de 11 de octubre de 2017: https://boe.es/diario_boe/txt.php?id=BOE-A-2017-11637

- Ley 11/2003, de 19 de marzo, de Protección Animal en la Comunidad Autónoma de Aragón. «BOA» núm. 35, de 26 de marzo de 2003. «BOE» núm. 96, de 22 de abril de 2003. Referencia: BOE-A2003-8225: https://www.boe.es/buscar/pdf/2003/BOE-A-2003-8225-consolidado.pdf

- Ley 12/2012, de 21 de junio, contra el Dopaje en el Deporte. Comunidad Autónoma del País Vasco «BOPV» núm. 126, de 28 de junio de 2012. «BOE» núm. 160, de 5 de julio de 2012. Referencia: BOE-A-2012-9010 : https://www.boe.es/buscar/pdf/2012/BOE-A-2012-9010-consolidado.pdf 
- Ley 7/1990, de 28 de diciembre, de protección de los animales domésticos. Comunidad Autónoma de Castilla-La Mancha «DOCM» núm. 1, de 02 de enero de 1991 «BOE» núm. 93, de 18 de abril de 1991 Referencia: BOE-A-1991-9406 : https://www.boe.es/buscar/pdf/1991/BOE-A-1991-9406consolidado.pdf

- Ley 7/2020, de 31 de agosto, de Bienestar, Protección y Defensa de los Animales de Castilla-La Mancha. https://docm.castillalamancha.es/portaldocm/descargarArchivo.do?ruta=2020/09/07/pdf/2020_615 4.pdf\&tipo=rutaDocm

\subsection{Otras fuentes}

Animal Welfare Act 2006 (Department for Environment Food and Rural Affairs). Página web : https://www.gov.uk/guidance/animal-welfare [Última consulta: 21 de noviembre de 2020 ]

- Breed-Specific Respiratory Disease In Dogs: From Bulldogs To Terriers. Página web: https://todaysveterinarypractice.com/breed-specific-respiratory-disease-dogs-bulldogsterriers/?fbclid=IwAR3fSupRmy3gBeve5jZiVjxlRILS2-wFJ2PtHkJAxdL3hcYKdTnwVjrIsWY [Última consulta: 6 de diciembre de 2020].

- Comunicado de la FEG. La ley de bienestar animal castellano manchega, permite el entrenamiento de galgos con vehículos a motor (2020). Página web : https://www.fedegalgos.com/la-ley-debienestar-animal-castellano-manchega-permite-el-entrenamiento-de-galgos-con-vehiculos-amotor/ [ Última consulta: 20 de noviembre de 2020]

- DIAZ, A. Porcentaje de hogares que tenían perro en España de 2008 a 2019. Statista (2020). Página web: https://es.statista.com/estadisticas/1045371/porcentaje-de-hogares-con-perro-en-espana/ [Última consulta : 25 de noviembre de 2020]

- Estudio sobre Abandono y Adopción de animales de compañía del año 2018, publicado por la Fundación Affinity en 2019. Página web: https://www.fundacionaffinity.org/observatorio/whitepaper-el-nunca-lo-haria-2019-estudio-abandono-adopcion-perrosgatos-espana [Última consulta : 20 de noviembre de 2020]

- FATJÓ, J. Estudio "El nunca lo haría" de la Fundación Affinity sobre el abandono, la pérdida y la adopción de animales de compañía en España 2018: interpretación de los resultados (2018). Página web: $\quad$ https://www.fundacion-affinity.org/sites/default/files/white-paper-abandono-2019.pdf [Última consulta : 18 de noviembre de 2020]

- GAEDE, C. EBBRECHT, T. Galgo español - Le lévrier Espagnol (2019) 93

- GUILLAUME, A. Le poids des mots/maux autour de la sentience animale: différences sémantique et traductologique entre bien-être et bientraitance, en Le bien-être animal : de la science au droit (2018)

- KOSCINCZUK, P. Domesticación, bienestar y relación entre el perro y los seres humanos. Revista Veterinaria. ISSN. (2017). (papel): 1668-4834. ISSN (on line) 1669-6840

- LOGAN, M. Training dogs with help of the shock collar: short and long term behavioural effects. AVSAB (2012) 